\title{
O uso das TIC durante a pandemia de covid-19 no ensino de matemática
}

\author{
The use of ICT during the covid-19 pandemic in mathematics teaching \\ Jussanã Gomes dos Santos \\ Leydiane Rodrigues dos Santos Gonçalves \\ Valdinei Cezar Cardoso
}

\begin{abstract}
Resumo: No presente momento, o mundo vivencia uma condição atípica de isolamento social que fez com que a nossa rotina fosse modificada em várias áreas inclusive na educação. Assim, houve a necessidade de utilizar o ensino remoto para dar continuidade ao calendário letivo da rede pública estadual de ensino do estado do Espírito Santo, Brasil, devido ao distanciamento social. Os recursos educacionais digitais desempenharam um papel importante nas metodologias educacionais adotadas. Este trabalho se configura como uma pesquisa qualitativa e tem por objetivo compreender como o ensino remoto tem modificado as práticas no ensino da matemática em duas turmas do oitavo ano do Ensino Fundamental, uma municípios de Linhares-ES e outra em São Mateus-ES. Quais os métodos e as ferramentas que têm auxiliado na aprendizagem desta disciplina, no período da pandemia de COVID19? E como as tecnologias têm influenciado no âmbito escolar? Para alcançar os objetivos, foi realizada uma entrevista com duas professoras de matemática, uma do município de São Mateus e a outra do município de Linhares, onde relataram como está sendo trabalhar de forma remota e quais os desafios enfrentados neste período. Como resultado, temos que as ferramentas mais usadas foram: Google Sala de Aula, Google Meet, Whatsapp, vídeos do YouTube e Formulários Google. Foi constatado também que o ensino remoto influenciou de aneira considerável as práticas educacionais das docentes, quebrando os paradigmas existentes antes da pandemia sobre o uso das tecnologias na educação.
\end{abstract}

Palavras chave: Tecnologias Digitais, Ensino Remoto, Google Sala de Aula.

Abstract: At the present time, the world is experiencing an atypical condition of social isolation that has changed our routine in several areas, including education. Thus, there was a need to use remote teaching to continue the academic calendar of the state public school system in the state of Espírito Santo, Brazil, due to social distancing. The digital educational resources have played an important role in the educational methodologies adopted. This work is a qualitative research and aims to understand how remote teaching has modified practices in the teaching of mathematics in two eighth grade classes at Middle School, one in Linhares-ES and another in São Mateus-ES. What are the methods and tools that have helped you learn this discipline during the COVID-19 pandemic? And how have technologies influenced the school environment? To achieve the objectives, an interview was conducted with two mathematics teachers, one from the municipality of São Mateus and the other from the municipality of Linhares, where they reported on how it is working remotely and what the challenges are facing in this period. As a result, we have that the most used tools were: Google Classroom, Google Meet, Whatsapp, YouTube videos and Google Forms. It was also found that remote teaching has considerably influenced teachers' educational practices, breaking the paradigms that existed before the pandemic about the use of technologies in education.

Keywords: Digital Technologies, Remote Education, Google Classroom 


\section{Introdução}

Frente ao atual cenário de pandemia mundial provocado pela COVID$19^{1}$, muitos educadores e estudantes modificaram os meios utilizados para a comunicação e a aprendizagem. Atualmente as Tecnologias da informação e Comunicação (TIC), têm um fundamental papel, como ferramenta para o desenvolvimento da educação, que agora acontece por meio de atividades não presenciais, com a utilização de aparelhos eletrônicos, Oliveira et al. (2020) descreve que os efeitos causados pela pandemia modificaram a sociedade e também afetaram "[...] o processo de escolarização de todas as crianças e adolescentes, em todas as etapas e níveis da educação formal, no Brasil e no mundo" (OLIVEIRA et al.2020, p. 2).

As modificações realizadas pela inserção das TIC e o acesso à internet, têm melhorado significativamente as áreas de conhecimento humano, pois elas desmistificam o conceito de que para se aprender é preciso estar em lugar específico e em horário determinado (MORAN, 2013). Frente ao atual cenário, elas possibilitaram que diferentes áreas retomassem suas tarefas cotidianas, das quais estavam limitadas a serem realizadas presencialmente, devido ao isolamento social no Estado do Espírito Santo e em várias outras partes do mundo.

Muitas escolas públicas ou privadas foram obrigadas a transformar sua maneira de mediar o processo de ensino e de aprendizagem, tendo como principal ferramenta pedagógica as TIC. Para cumprir o calendário letivo e promover a necessária interação entre as famílias e as escolas, bem como proporcionar aos alunos um guia para o seu aprendizado, visto que, o modo de aprender, deixou de ser, majoritariamente, com aulas presenciais e tem ocorrido por meios digitais.

Os campos influenciados pela pandemia são grandes, dentre eles um dos mais afetados é o da educação, assim, essa pesquisa tem por objetivo mostrar a vivência de duas professoras de matemática da rede Estadual de

${ }^{1}$ Doença causada por um vírus da família dos coronavírus e provoca sintomas como febre, tosse e dificuldade respiratória. Os primeiros casos da doença surgiram no final do ano de 2019, na China. No primeiro semestre de 2020, a doença já havia atingindo todos os continentes, sendo classificada como uma pandemia. Fonte: <https://mundoeducacao.uol.com.br/doencas/covid-19.htm>. 
Educação do Espírito Santo, no presente cenário de pandemia. Como está sendo o ensino de matemática? Quais as dificuldades enfrentadas pelas docentes, suas experiências e descobertas com o ensino remoto?

Inicialmente julgamos relevante, conhecer algumas discussões acerca do assunto que será abordado neste artigo. Veiga (2006) menciona que o professor deve procurar caminhos para modificar sua prática profissional, deixando para trás aquela didática de apenas ensinar o conteúdo e caminhar em direção ao seu verdadeiro papel que é o de mediador, mentor e facilitador, buscando priorizar e intermediar o acesso do aluno ao conhecimento. Para que isso seja possível, Veiga (2006) descreve que o professor deve constantemente aprimorar suas metodologias de ensino, buscando atender as necessidades emergentes.

Atualmente foi necessário mudar bruscamente as práticas, antes presenciais e tradicionais, para a exclusivamente remota ${ }^{2}$, não queremos aqui afirmar que o uso de TIC resolverá os problemas da educação, mas coadunamos com Borba e Penteado (2001), que afirmam que as ferramentas digitais podem ser grandes aliadas para aprimorar as práticas de ensino, superando os encaminhamentos tradicionais, conforme delineado por Chaves,

O que é particularmente fascinante nas novas tecnologias disponíveis hoje, em especial na Internet, e, dentro dela, na $w e b$, não é que, com sua ajuda, seja possível ensinar remotamente ou à distância, mas, sim, que elas nos ajudam a criar ambientes ricos em possibilidades de aprendizagem nos quais as pessoas interessadas e motivadas podem aprender quase qualquer coisa sem, necessariamente, se envolver num processo formal e deliberado de ensino (CHAVES, 2017, p. 3).

Desse modo, iremos buscar compreender como o ensino remoto e as tecnologias têm modificado as práticas no ensino da matemática nos municípios de Linhares e São Mateus? E quais os métodos e ferramentas têm auxiliado na aprendizagem desta disciplina? Para isso, foi necessário inicialmente conhecer o que a literatura registra sobre a utilização de tecnologias na Educação Matemática.

2 Podendo ocorrer por meio de meios digitais ou não, mas essencialmente remoto. 


\section{O uso das TIC na educação no Espírito Santo}

Diante deste cenário de pandemia no Brasil, uma das medidas usadas pela Secretária Estadual de Educação do Espírito Santo, foi buscar propostas para permitir a continuidade dos processos de ensino e aprendizagem, por meio de aulas na modalidade remota onde estudantes, professores e demais envolvidos no processo de ensino pudessem ter acesso às salas de aula.

Para isso, foi desenvolvido o aplicativo EscoLAR, que permitiu a utilização do Whatsapp e do Google Sala de Aula, para a sistematização de salas de aulas online, com transmissões de aulas pela TV e pelo YouTube, nas redes e canais que foram contratados para prestar um serviço que atingisse $o$ maior número possível de estudantes. Marques (2020, p. 5) detalha que,

As mudanças emergentes que ocorreram no processo de ensino frente o atual contexto da pandemia causada pelo novo coronavírus, levaram a adoção de metodologias, até então, não adotadas por muitos professores em seus ambientes de ensino. O que fez urgir a necessidade de inovação perante o ato de lecionar, buscando alternativas inovadoras para levar conhecimento aos seus alunos, com o intuito, sobretudo, de prover autonomia aos estudantes no seu processo de aprendizagem.

Portanto devemos moldar nossas maneiras de nos comunicar com os alunos de forma a proporcionar a melhor seleção de ferramentas, sejam elas físicas ou digitais que proporcionem uma filtragem de materiais para o ensino e a aprendizagem de matemática, o que vamos discutir um pouco na sequência deste trabalho.

\section{$O$ revés no uso das TIC}

Existe uma preocupação, por parte de alguns professores, sobre as mais recentes TIC, pois há um interesse em verificar se elas são úteis ao processo de ensino e de aprendizagem. Por conseguinte, muitos professores tendem a pensar nas mais antigas maneiras de abordar o processo educativo como algo seguro e eficaz. Alguns docentes acreditam que velhos métodos são mais eficazes do que outros, prevalecendo assim uma educação puramente 
tradicional que foca a transmissão de conteúdos e uma comunicação puramente superficial (MAGALHÃES; MILL, 2013, p. 2).

No contexto dos debates sobre o uso das TIC no âmbito educacional, especialmente as digitais, entre os docentes há dois pensamentos:

[...] por um lado, há boa parte que vê as TIC como aquelas que empurram os estudantes para uma cultura do consumismo e roubam os alunos da sala de aula - quando não fisicamente, pelo menos nos seus aspectos de aprendizagem ou desenvolvimento intelectual. Como resultado, cria-se um movimento de resistência ao uso pedagógico das TIC pelas suas possíveis repercussões negativas ao educando. Outra parcela de educadores, por outro lado, acredita que as TIC podem ter muita serventia, desde que "esterilizadas" de suas características "mundanas" e convenientemente "adaptadas" aos fins nobres da educação "pura" (MAGALHÃES; MILL, 2013, p. 2).

Diante, do exposto até o momento, podemos constatar que ainda há resistência quanto ao uso das TIC no âmbito educacional, fato este estudado em diversas pesquisas Borba e Penteado (2001), Neto e Mendes (2007), Pacheco e Lopes (2018), Zanella e Lima (2017), entre tantas outras. Borba, Scucuglia e Gadanidis (2014) ressaltam que as tecnologias modificaram as relações de ensino que ocorrem nas escolas, entre alunos e professores. Bartolo e Araújo (2017) afirmam que o uso de computadores e celulares tem feito parte da vida de muitos jovens da atualidade, devido às suas inúmeras funcionalidades como: jogos, redes sociais, filmes, séries e demais recursos online.

Deste modo, tornou-se imprescindível mencionar o quão importante as Tecnologias de Informação e Comunicação estão sendo em meio à pandemia da COVID-19, não queremos aqui salientar que antes elas não eram profícuas, mas sim, ressaltar a importância delas, neste período e que sem elas, seria muito mais difícil ou até mesmo inviável dar continuidade aos nossos sistemas de ensino formal.

Martins (2019) nos trazem que as tecnologias e a internet proporcionam, aos discentes, gerenciar seu aprendizado por processos formais ou não, sem uma limitação de espaço e tempo, com as mídias digitais disponíveis, indo além dos muros da escola. Assim, segundo Martins(2019), cabe à escola 
proporcionar aos alunos, selecionar em meio a diversidade das tecnologias, maneiras de apurar as informações mais pertinentes, possibilitando um debate crítico e eficiente.

Face ao que menciona Martins (2019), os alunos têm inquirido paulatinamente as TIC para gerenciar sua aprendizagem, tornando-se construtores do seu próprio conhecimento, mas vale ressaltar as armadilhas que as mídias, redes sociais e demais meios digitais nos trazem, principalmente no que se refere ao conhecimento e à informações verídicas, por mais que se perseverem alunos que saibam selecionar tais conteúdos, também existem aqueles, que não consegue filtrar o que é ou não relevante ao seu aprendizado e assim, proporcionam grandes prejuízos a sua aprendizagem, cabendo ao professor direcionar estes alunos para que consigam seguir com os estudos.

Dentre os variados conjuntos de consequências que tornam a matemática uma disciplina importante no currículo, a sociedade atribui a ela uma importância grande. Corriqueiramente têm surgido várias ideias e tendências para aprimorar seu ensino e sua aprendizagem, visto que além de sua relevância, ela também é vista, por muitos, como uma disciplina complexa e difícil de aprender (MARTINS, 2009) ainda ressalta que,

O desenvolvimento das Tecnologias de Informação e Comunicação (TIC) veio acrescentar a todo esse movimento uma verdadeira revolução no ensino da disciplina. Numa Sociedade marcada pela utilização massiva das TIC, a Matemática surge como uma área disciplinar essencial para a formação e integração dos jovens na vida profissional activa e aqui reside a razão fundamental da importância que a Sociedade, em geral, atribui à disciplina (MARTINS, 2009, p. 1).

Assim, com a chegada da pandemia e com as mudanças bruscas no ensino, das quais os professores, pedagogos e demais profissionais da educação, em sua grande maioria tiveram que lidar com outra modalidade de ensino, novos desafios, dificuldades e aprendizagens que surgiram.

Por isso, acreditamos ser relevante trazer à comunidade científica as experiências em trabalhar com o uso das TIC no ensino de matemática e citar 
algumas ferramentas que auxiliaram neste momento de ensino remoto que estamos vivenciando.

\section{Metodologia}

Nosso trabalho, se caracteriza como uma pesquisa de cunho qualitativo, a coleta de dados ocorreu por meio de um questionário respondido por duas professoras de matemática da Rede Estadual de Educação do Espírito Santo. Ambas residem no Estado, mas em diferentes municípios, uma em Linhares e outra em São Mateus, sendo denominadas por professora A e professora B, respectivamente, as docentes lecionam em turmas do oitavo ano do Ensino Fundamental.

O questionário foi composto por 07 perguntas, com objetivo de conhecer: a realidade vivenciada pelas docentes nesse momento; se elas utilizam as TIC na sua prática; o ponto de vista das professoras a respeito da utilização das tecnologias no ensino de Matemática. 
Questão 01) Identificação, onde trabalha e com quais turmas.

Questão 02) Você poderia descrever sua prática pedagógica (no ano de 2020) antes do início das aulas remotas?

Questão 03) Consideração o atual cenário provocado pela COVID-19 e isolamento social, na sua opinião suas práticas de ensino foram modificadas?

Questão 04) Você utilizava as ferramentas tecnológicas na sala de aula presencialmente? Descreva a utilização, se possível.

Questão 05) Qual importância você daria as tecnologias para suas práticas pedagógicas anteriormente e atualmente?

Questão 06) Quais ferramentas digitais têm utilizado durante a pandemia para dar continuidade no processo de ensino e aprendizagem de matemática?

Questão 07)

\begin{tabular}{|c|c|c|c|}
\hline $\begin{array}{c}\text { TIPO DE } \\
\text { ATIVIDADE* }\end{array}$ & PRESENCIAL & ENSINO REMOTO & DIFICULDADES \\
& & & \\
\hline
\end{tabular}

${ }^{*}$ No tipo de atividade, os autores buscaram conhecer sobre os elementos:

Aula expositiva; Resolução de exercícios; Avaliação; Interação; Tecnologias; Livro

Didático; Materiais Complementares; Acesso aos meios tecnológicos; Mitos superados; Aprendizados e descobertas.

Fonte: Os autores.

\section{Resultados e discussões}

Nesta seção iremos apresentar os dados coletados por meio das entrevistas, separamos os resultados em práticas das docentes, antes e durante o ensino remoto. É importante ressaltar que, quando nos referimos ao ensino presencial estamos nos referindo ao tempo cronológico que ocorreu antes da pandemia (onde as aulas eram exclusivamente presenciais) e no que diz respeito ao ensino remoto, estamos nos referindo ao período em que as aulas ocorreram exclusivamente de forma remota, sejam elas mediadas pelas tecnologias digitais (celular, computador, tablet entre outros) ou a tecnologias não digitais, tais como atividades impressas que os alunos buscavam na 
secretaria da escola. Ressaltamos que a entrevista com as docentes ocorreu antes que a Secretária Estadual de Educação do Espírito Santo, decretassem ${ }^{3}$ a volta às aulas presenciais, de modo opcional.

\section{ANTES DO ENSINO REMOTO}

Com as questões 02, 04, 05 e 07 nós buscamos conhecer as práticas realizadas pelas docentes no ensino presencial.

Inicialmente buscamos conhecer como era a prática pedagógica das docentes antes do início da pandemia, ao responderem com a Questão 02, as professoras relataram que as aulas eram, em sua grande maioria, expositivas e dialogadas, em alguns momentos utilizavam jogos, computadores e outras ferramentas digitais, mas isso não ocorria sempre devido à necessidade de cumprir o currículo vigente,

No início do ano de 2020, comecei a inserir avaliações diagnósticas através do Google Formulário, e percebi a dificuldade dos alunos em manusear ferramentas digitais aquém das redes sociais, muitos apresentaram dificuldade em inserir o símbolo '@', desconhecimento de como ligar um computador (PROFESSORA A, entrevista em 2020).

Na Questão 04, os pesquisadores buscaram identificar se as docentes utilizavam das tecnologias digitais no âmbito escolar presencial, as duas professoras, afirmaram que sim, no entanto, a docente B enfatizou dificuldades encontradas, ao utilizar as tecnologias digitais no ensino presencial, nas palavras da docente "[...] a escola não dispõe de um laboratório de informática nem uma internet de boa qualidade, [...] dispõe de ChromeBooks, mas nem todos funcionam adequadamente [...]" (PROFESSORA B, entrevista em 2020).

As dificuldades estruturais e técnicas apontadas pela professora, são recorrentes, há muitos anos, Borba e Penteado (2001), apontaram essas questões, por meio desse comparativo, podemos constatar que as dificuldades encontradas na escola, podem demorar anos para serem resolvidas. Não é nosso objetivo, procurar conhecer o motivo da demora em resolver problemas estruturais, mas julgamos importante, chamar atenção do leitor para este fato.

\footnotetext{
3 Mais informações em: <https://www.es.gov.br/Noticia/aulas-presenciais-para-o-ensino-medioda-rede-estadual-retornam-no-proximo-dia-13-de-outubro>.
} 
$\mathrm{Na}$ Questão 07, buscamos conhecer às dificuldades, enfrentadas pelas docentes antes da pandemia, para as professoras as maiores dificuldades do ensino presencial, estão na indisciplina dos alunos, conversas paralelas, pouca participação da família, quantidade de computadores insuficiente para uso, internet de baixa velocidade e a cobrança pelo cumprimento integral do currículo.

Assim, ao entrevistarmos as docentes, buscamos conhecer quais são as práticas de ensino utilizadas por elas em suas aulas, em especial, no que tange ao uso das tecnologias digitais, a professora afirma que utiliza, mas

[...] poucas vezes! Não por não querer usar ou não ter habilidade com elas, mas sim, porque a escola não dispõe de um laboratório de informática nem uma internet de boa qualidade, a escola possui alguns Chromebooks, mas nem todos funcionam adequadamente [...] (PROFESSORA B, entrevista em 2020).

A fala da professora descreve dificuldades na utilização das TIC, mesmo quando existe a iniciativa docente, há empecilhos físicos, que devem ser superados no âmbito educacional, tal como a falta de infraestrutura e manutenção dos equipamentos. Tais dificuldades não são particulares das escolas investigadas em nosso trabalho, como apontam Zanella e Lima (2017) em seu trabalho. A docente $B$ descreve que as tecnologias digitais são muito importantes na sua prática pedagógica, pois com a utilização dessas ferramentas, no seu entendimento, podem moldar o contexto educacional e tornar as aulas mais interessantes para os alunos (PROFESSORA B, entrevista em 2020).

Diante de todos esses questionamentos, foi relevante apurar a opinião da docente quanto à importância das tecnologias para suas práticas pedagógicas, anteriormente a professora A disse que:

Antes, as tecnologias no ensino, havia incentivo para utilização, porém dependia do conhecimento e vontade de cada docente (PROFESSORA A, entrevista em 2020).

De acordo com a docente, as aulas presenciais ocorriam de forma expositiva e dialogada (PROFESSORA A, entrevista em 2020). As dificuldades 
enfrentadas por ela nas aulas, sejam presenciais ou remotamente por meios digitais são que

[...] poucos alunos expõem dúvidas no momento da explicação, nas duas modalidades de ensino. Sempre os mesmos alunos que tem dúvidas no presencial, também apresentam dúvidas na modalidade à distância (PROFESSORA A, entrevista em 2020).

Não são todos os educandos que possuem esta resistência e isso fica claro em sua fala anterior quando nos diz que "[...] os mesmos alunos que tem dúvidas no presencial, também apresentam dúvidas na modalidade à distância" (PROFESSORA A, entrevista em 2020), ou seja, aqueles que eram dedicados anteriormente ainda apresentam esta característica no ensino de forma remota. Bartolo e Araújo (2017) defendem que as TIC fazem parte da vida dos estudantes e muitos sabem manusear, tanto quanto um professor ou até mais.

Mas é interessante considerarmos, neste momento de pandemia, que mesmo que o uso da tecnologia esteja em alta e que muitos têm facilidades quanto ao seu uso, existem alguns discentes que têm dificuldades para este acesso, levando à prejuízos na aprendizagem dos estudantes.

\section{DURANTE O ENSINO REMOTO}

Com as questões 03, 05, 06 e 07 do questionário, os pesquisadores buscaram conhecer as práticas realizadas pelas docentes durante o ensino remoto, em especial com a utilização das TIC.

$\mathrm{Na}$ Questão 03, buscamos compreender como o isolamento social, havia modificado as práticas das docentes? As duas afirmaram que nas palavras da professora A "[...] minhas práticas de ensino foram modificadas, principalmente pelo fato de ter que utilizar de maneira majoritária as tecnologias digitais, em especial, os serviços oferecidos pela plataforma Google" (PROFESSORA A, entrevista em 2020). Podemos constatar que as tecnologias digitais estão sendo fundamentais neste período, visto que por meio delas é que está sendo possível dar prosseguimento ao processo de ensino e de aprendizagem.

$\mathrm{Na}$ Questão 07, teve por objetivo conhecer como eram realizadas algumas situações de ensino remoto e as dificuldades encontradas. 
No momento atual, um contexto de distanciamento social, as aulas acontecem de modo remoto, seja com uso das tecnologias ou não, a professora $B$ afirmou que devido às mudanças sociais impostas pela COVID19 , no que concerne aos processos de ensino, "a pandemia fez com que eu aprendesse várias outras técnicas de ensino além de aprimorar outras já conhecidas" (PROFESSORA B, entrevista em 2020).

$A$ docente $B$ afirma que, no cenário de ensino remoto, ocorreram aprendizagens no que se refere ao uso de tecnologias digitais, pois a comunidade escolar passou a ter contato mais frequente com métodos de ensino mediados pela tecnologia, assim pode ser observado que alguns alunos demonstraram maior facilidade em se comunicar e até mesmo na apresentação de trabalhos, se sentiram mais seguros,

Foi percebido também, por meio de trabalhos remotos, que alguns alunos que não se destacavam no presencial e tinham vergonha de perguntar e se impor, estão se destacando no ensino à distância, alunos que não apresentavam jamais um trabalhos no presencial hoje fazem isso online com a maior facilidade e com habilidades surpreendentes, foi percebido também que o ensino totalmente online nesse período limitou alguns alunos a evoluírem com a aprendizagem, pois eles não possuem iniciativa própria nem habilidades para estudar sozinhos, muitos deles precisam ser cobrados diariamente para que possam desenvolver as tarefas e adquirir algum aprendizado [...] (PROFESSORA B, entrevista em 2020).

Como mencionado pela docente, houve aprendizagem e foram detectados pontos positivos e negativos no ensino remoto, pois alguns alunos que não tinham dificuldades no presencial, por meio remoto apresentaram algumas dificuldades, por exemplo, a dificuldade de acesso ou de utilização de ferramentas digitais.

No modalidade remota as professoras relataram que as maiores dificuldades enfrentadas foram: verificar a aprendizagem e se foram eles mesmos que realizaram a tarefa, falta de compromisso, a interação em si, o diálogo recíproco a troca de informações e dúvidas, alguns alunos não dispõem de aparelhos tecnológicos, instabilidade da internet em alguns momentos, visto que a tecnologia deixou de ser um suporte às aulas presenciais e passou a ser 
um dos únicos recursos disponíveis para que as aulas pudessem ser continuadas.

A falta de habilidade com alguns recursos tecnológicos e as limitações de algumas ferramentas tecnológicas. A verificação do uso dos softwares e se realmente os alunos estavam usando-os para aprimorar a aprendizagem dos discentes.

Foi relevante apurar (Questão 05) a visão das docentes quanto à importância dada por elas para as tecnologias para suas práticas pedagógicas, a professora $\mathrm{A}$ afirmou que,

[...] Vejo que atualmente, neste cenário de pandemia, os profissionais que ainda demonstravam alguma resistência ao uso das tecnologias digitais (TD) nos processos de ensino e aprendizagem presenciais, tiveram como única opção a utilização desses meios para continuar lecionando (PROFESSORA A, entrevista em 2020).

A pandemia da COVID-19 trouxe uma obrigatoriedade no uso das tecnologias, corroborando com a fala da professora $A$, mesmo que não adeptos a tal prática, alguns professores compeliram de tal realidade para prosseguir como as aulas e o ano letivo.

$\mathrm{Na}$ Questão 06, quando questionadas sobre as ferramentas mais utilizadas durante a pandemia, a docente A apontou o Google Sala de Aula, o Google Meet, o Whatsapp, Vídeos do YouTube e Formulários Google.

Em meio ao cenário de pandemia é perceptível pela fala da professora, que tanto no ensino presencial quanto no remoto, os discentes têm demonstrado pouco interesse quanto às aulas de matemática e que o cenário não mudou o compromisso e a dedicação com as aulas, isso fica mais evidente quando ela nos diz que "assim como no presencial, há uma resistência dos alunos em resolver as atividades propostas ou a tirar dúvidas" (PROFESSORA A).

Mesmo em meio ao avanço tecnológico, ainda nos prendemos às velhas práticas de ensino e temos dificuldades em moldá-las a diferentes contextos, e isso fica evidente quando a docente $A$ é questionada quanto à resolução de exercícios, que segundo ela acontece "quando os alunos tinham dúvidas sobre 
os exercícios, mandavam foto para a professora pedindo ajuda. O trabalho era predominantemente individual" (PROFESSORA A, entrevista em 2020).

Outro fato que fica evidente na fala da professora $A$ é a interação dos discentes, que é mais visível nas aulas presenciais do que nas remotas. $E$ não só a interação física e emocional que foi observada pela docente $A$, mas também na realização das atividades, como é mencionado por ela quando diz que "na modalidade à distância os alunos interagem menos com a professora. Existem mais dúvidas em comparação com as aulas presenciais" (PROFESSORA A, entrevista em 2020).

Outro fato relevante foi ao acesso às TIC, muitos estudantes têm limitação ao acesso à internet, bem como celulares, computadores para realizar as atividades remotas, tornando assim ainda mais difícil sua aprendizagem por meio remoto.

A docente $A$ também foi questionada quanto aos recursos tecnológicos utilizados, se ela já usava antes da pandemia, ela ressaltou que "sim, utilizava ferramentas como o Khan Academy, Google Formulário e resolução de atividades com auxílio da mesa digitalizadora" (PROFESSORA A, entrevista em 2020).

Veiga (2006) mostra que o professor deve mudar suas práticas educacionais, deixando de usar aquela didática definida com papel de apenas ensinar o conteúdo e passando a assumir o seu verdadeiro papel que é o de mediador, mentor e facilitador, priorizando e intermediando o acesso do discente à informação, utilizar os recursos tecnológicos, para mesclar as aulas, faz com que os discentes se sintam mais motivados e atentos às informações que Ihe são passadas, na fala da professora A ela deixa claro que faz isso em suas aulas.

\section{Considerações finais}

Para concluirmos a discussão, mas jamais as inquietações, podemos constatar ao longo desta pesquisa que o ensino remoto modificou as práticas de ensino e isso fica evidente na fala da docente $A$, quando diz que suas práticas foram alteradas "principalmente pelo fato de ter que utilizar de maneira 
majoritária as tecnologias digitais, em especial, os serviços oferecidos pela plataforma Google" (PROFESSORA A, entrevista em 2020).

A pandemia da COVID-19 teve forte influência para a quebra dos paradigmas que professores e alunos, bem como toda a comunidade escolar, tinham no que tange ao uso de tecnologias digitais na educação, muitos foram obrigados a utilizá-la e precisaram aprender a usar os seus principais recursos.

Por meio desta pesquisa, podemos constatar que o ensino presencial e o ensino remoto, possuem características que podem ser exploradas no ambiente escolar, devemos enquanto professores tentar garantir amplo acesso e diversificar os métodos abordados no ensino para que os alunos possam se desenvolver como cidadãos de forma plena. Não existe uma metodologia de ensino perfeita, que irá solucionar todos os problemas, mas que cada uma possibilita e favorece os alunos de diferentes maneiras, conforme apontado também por Veiga (2006).

As ferramentas mais utilizadas, segundo as professoras, são o Google Sala de Aula, Google Meet, Whatsapp, Vídeos do YouTube e Formulários Google. Que foram e ainda são essenciais no desenvolvimento das atividades, bem como para manter o vínculo com os alunos.

É importante enfatizar a similaridade das informações dadas pelas professoras, pois mesmo atuando em cidades diferentes, foram notadas as mesmas limitações no uso e manuseio das mídias.

Concluímos, com a análise das entrevistas, o quão relevante é o uso das TIC no ensino e na aprendizagem em matemática, mas quando feito exclusivamente, sem o ensino presencial, traz prejuízos para alguns discentes. Muitos alunos, por terem algumas limitações em usar as TIC, se sentem frustrados e acabam por ser desinteressantes e pouco instigantes.

A análise dos nossos dados nos permite concordar com Veiga (2006), no sentido de que acreditamos que o professor deve constantemente aprimorar seus métodos de ensino, buscando atender às necessidades que vão surgindo, principalmente quando isso interfere no ensino e na aprendizagem. A relação entre estudantes e professores de forma presencial é muito importante, os discentes e os docentes ainda necessitam do ensino presencial para terem 
mais interação com os colegas e com os(as) professores(as). No entanto, a situação de isolamento social, imposta pela pandemia de COVID-19, nos deixa uma experiência de que é fundamental integrar ferramentas digitais nas aulas de matemática, sejam elas presenciais ou remotas.

\section{Referências}

BARTOLO, Mariana Guedes; ARAUJO, Thamiris Oliveira de. A Gamificação em apps educacionais: investigando as potencialidades de Memrise e Upmind para a aprendizagem da língua inglesa. SIMPÓSIO DE HIPERTEXTOS E TECNOLOGIA DA EDUCAÇÃ̃O, 7. Recife, 2017. Anais eletrônicos: Recife, UFPE, 2017. p. 691-713. $\quad$ Disponível em:< https://www.researchgate.net/publication/340081883 A Gamificacao em apps educacionais investigando as potencialidades de Memrise e Upmind para a aprendizagem da lingua inglesa>. Acesso em: 20 de ago.2020.

BORBA, Marcelo de Carvalho; PENTEADO, Miriam Godoy. Informática e Educação Matemática. 2 ed. Belo Horizonte: Autêntica, 2001.

BORBA, Marcelo de Carvalho; SILVA, Ricardo Scucuglia Rodrigues da; GADANIDIS, George. Fases das Tecnologias Digitais em Educação Matemática: sala de aula e internet em movimento. Belo Horizonte: Autêntica, 2014.

CHAVES, Eduardo O C. A Tecnologia e a Educação. 2017. Disponível em:<http://smeduquedecaxias.ri.gov.br/nead/Biblioteca/Forma\%C3\%A7\%C3\% A30\%20Continuada/Tecnologia/chaves-tecnologia.pdf>. Acesso em: 21 jul. 2020.

MAGALHÃES, Cláudio Márcio; MILL, Daniel. Elementos para reflexões sobre educação, comunicação e tecnologia: nada é tão novo sobre redes, linguagem e 2013.2 Disponível em:<https://periodicos.sbu.unicamp.br/ojs/index.php/etd/article/view/1285/pdf>. Acesso em: 21 jul. 2020.

MARQUES, Ronualdo. A ressignificação da educação e o processo de ensino e aprendizagem no contexto de pandemia da covid-19. Boletim de conjuntura (boca), ano II, vol. 3, n. 7, 2020. Disponível em:< https://revista.ufrr.br/boca/article/view/Marques>. Acesso em: 29 Jul. 2020.

MARTINS, Zélia. As TIC no ensino-aprendizagem da Matemática. In: Anais do $X$ Congresso Internacional Galego-Português de Psicopedagogia. Universidade do Minho. Portugal. 2009. p. 2727-2742. Disponível em: $<$ https://www.educacion.udc.es/grupos/gipdae/documentos/congreso/xcongres o/pdfs/t7/t7c200.pdf>. Acesso em: 15 set. 2020. 
MORAN, José. A integração das tecnologias na educação. Campinas: Papirus. $2013 . \quad$ Disponível em:< http://www.eca.usp.br/prof/moran/site/textos/tecnologias eduacacao/integracao .pdf>. Acesso em: 18 ago. 2020.

NETO, Alaim Souza; MENDES, Geovana Mendonça Lunardi. Os usos das tecnologias digitais na escola: discussões em torno da fluência digital e segurança docente. Revista e-Curriculum, [S.I.], V. 15, n. 2, p. 504-523, jun. 2017. Disponível em: <https://revistas.pucsp.br/curriculum/article/view/30397>. Acesso em: 22 jul. 2020.

OLIVEIRA, Antonia Soares Silveira e; NETO, Augusto Brito Araújo; OLIVEIRA, Lygia Maria Silveira e. Processo ensino aprendizagem na educação infantil em tempos de pandemia e isolamento. Ciência Contemporânea, v. 1, n. 6, p. 349-364, 2020. Disponível em: < http://cienciacontemporanea.com.br/index.php/revista/article/view/32>. Acesso em: 21 jul. 2020.

PACHECO, Márcia Leão da Silva; LOPES, Rosemara Perpétua. Resistência à integração das tic à educação básica pública brasileira e sua relação com a formação continuada. CIET: EnPED, [S.I.], maio 2018. Disponível em: $<$ https://cietenped.ufscar.br/submissao/index.php/2018/article/view/117>.

Acesso em: 20 jul. 2020.

VEIGA, IIma Passos Alencastro. Técnicas de ensino: novos tempos, novas configurações. Campinas: Papirus Editora, 2006.

ZANELLA, Brenda Rafaela Devens; LIMA, Maria de Fátima Webber Prado. Refletindo sobre os Fatores de Resistência no Uso das TICs nos Ambientes Escolares. Scientia cum Industria, v. 5, n. 2, p. 78-89, 2017. Disponível em: $<$ http://www.ucs.br/etc/revistas/index.php/scientiacumindustria/article/view/5284 >. Acesso em: 18 ago. 2020.

\section{Entrevistas}

PROFESSORA A. Entrevista concedida às autoras deste trabalho, São Mateus, 15 set. 2020.

PROFESSORA B. Entrevista concedida às autoras deste trabalho, São Mateus, 16 set. 2020.

\section{Sobre os Autores}

\section{Jussanã Gomes dos Santos}

jussanags@hotmail.com

\section{Leydiane Rodrigues dos Santos Gonçalves}

leydianerodrigues_15@hotmail.com 


\section{Valdinei Cezar Cardoso}

valdinei.cardoso@ufes.br 